\title{
A WAVE-1 and WRP Signaling Complex Regulates Spine Density, Synaptic Plasticity, and Memory
}

\author{
Scott H. Soderling, ${ }^{1,2}$ Eric S. Guire, ${ }^{2}$ Stefanie Kaech, ${ }^{3}$ Jon White, ${ }^{1,2}$ Fang Zhang, ${ }^{1,2}$ Kevin Schutz, ${ }^{1,2}$ \\ Lorene K. Langeberg, ${ }^{1,2}$ Gary Banker, ${ }^{3}$ Jacob Raber, ${ }^{4}$ and John D. Scott ${ }^{1,2}$ \\ ${ }^{1}$ Howard Hughes Medical Institute, ${ }^{2}$ Vollum Institute, ${ }^{3}$ Center for Research on Occupational and Environmental Toxicology, and ${ }^{4}$ Departments of \\ Behavioral Neuroscience and Neurology and Division of Neuroscience, Oregon National Primate Research Center, Oregon Health \& Science University, \\ Portland, Oregon 97239
}

The scaffolding protein WAVE-1 (Wiskott-Aldrich syndrome protein family member 1) directs signals from the GTPase Rac through the Arp2/3 complex to facilitate neuronal actin remodeling. The WAVE-associated GTPase activating protein called WRP is implicated in human mental retardation, and WAVE-1 knock-out mice have altered behavior. Neuronal time-lapse imaging, behavioral analyses, and electrophysiological recordings from genetically modified mice were used to show that WAVE-1 signaling complexes control aspects of neuronal morphogenesis and synaptic plasticity. Gene targeting experiments in mice demonstrate that WRP anchoring to WAVE-1 is a homeostatic mechanism that contributes to neuronal development and the fidelity of synaptic connectivity. This implies that signaling through WAVE-1 complexes is essential for neural plasticity and cognitive behavior.

Key words: WAVE-1; WRP; actin; Arp2/3; dendritic spine; synaptic plasticity

\section{Introduction}

The small-molecular-weight GTPases Rho, Rac, and Cdc42 (cell division cycle 42) function as molecular switches to modulate the activity of downstream cellular effectors (Etienne-Manneville and Hall, 2002). Rac signaling is synchronized by the WAVE (Wiskott-Aldrich syndrome protein family)/Scar (suppressor of cAMP receptor) family of scaffolding proteins (Machesky and Insall, 1998). The three WAVE isoforms (WAVE-1, WAVE-2 and WAVE-3) are modular proteins, each with an N-terminal Scar homology domain (SHD), a central proline-rich region, and a C-terminal Verprolin-Cofilin-Acidic (VCA) domain. These protein interaction modules permit assembly of multiprotein complexes. Proteomic and biochemical studies have shown that the SHD domain binds a core unit of four proteins that regulate Rac signaling at sites of actin reorganization (Eden et al., 2002; Innocenti et al., 2004; Steffen et al., 2004). The proline-rich region encompasses several recognition sites for Src homology 3 (SH3) domain-containing proteins including the Ableson tyrosine kinase (Abl) and the WAVE-associated Rac GTPaseactivating protein (GAP) called WRP [also MEGAP (mental disorder-associated GAP)/SrGAP3 (SLIT-ROBO Rho GTPase-

Received July 26, 2006; revised Nov. 17, 2006; accepted Nov. 19, 2006.

This study was supported by National Institutes of Health Grants DK44239 (J.D.S.), NS17112 (G.B.), AG20904 (J.R.), and NS27037 (T. R. Soderling). Support was also provided by Emergency Medical Foundation Grant AG-NS0201 (J.R.).

Correspondence should be addressed to either of the following: Scott H. Soderling, Department of Cell Biology, Duke University Medical Center, Durham, NC 27710, E-mail: s.soderling@cellbio.duke.edu; or John D. Scott, Vollum Institute L-474, Oregon Health \& Science University, Portland, OR 97239, E-mail: scott@ohsu.edu.

S. H. Soderling's present address: Department of Cell Biology, Duke University Medical Center, Durham, NC 27710.

DOI:10.1523/JNEUROSCI.3209-06.2006

Copyright $\odot 2007$ Society for Neuroscience $\quad$ 0270-6474/07/270355-11\$15.00/0 activating protein 3)] (Westphal et al., 2000; Soderling et al., 2002). The principal function of the VCA domain is to bind the Arp2/3 complex, a group of seven proteins that stimulate branched actin polymerization (Bear et al., 1998; Machesky and Insall, 1998). Arp2/3-mediated formation of a dense branched actin network is critical for membrane protrusion. Structural studies show that WAVE binding induces a conformational change in Arp2/3 to provide a template that nucleates branched actin polymerization (Volkmann et al., 2001; Rodal et al., 2005).

Accumulating evidence implies that WAVE complexes participate in neuronal development. Disruption of the WAVE gene in Drosophila causes morphological defects such as ectopic midline crossing and synapse undergrowth in the larval neuromuscular junction (Schenck et al., 2004). These results suggest that WAVE signaling may regulate axonal outgrowth and synapse development. Imaging studies have shown that mammalian WAVE-1 is present in the leading edges of lamellipodia in neuronal growth cones in which it may play a role in the organization of these structures (Nozumi et al., 2003). WAVE-1 knock-out mice exhibit deficits in sensorimotor function and perform poorly in cognitive tests (Soderling et al., 2003). Interestingly, some of these behavioral phenotypes overlap with the symptoms of a syndromic form of mental retardation in humans called $3 \mathrm{p}$ syndrome (Endris et al., 2002). Positional cloning techniques have shown that disruption of the WRP gene contributes to $3 \mathrm{p}$ syndrome (Endris et al., 2002). We have shown previously that WRP associates with WAVE-1 via a C-terminal SH3 domain and have found two stretches of proline-rich sequences between amino acids $320-332$ and $420-433$ that participate in these protein-protein interactions (Soderling et al., 2002).

Here, using the WAVE-1 knock-out mice as a model, we find that loss of this scaffolding protein impacts neuronal growth cone 
dynamics and morphology. Histological examination of the WAVE-1 knock-out mice revealed changes in spine density and electrophysiological analyses demonstrate abnormalities in synaptic plasticity. To establish whether the interaction between WAVE-1 and WRP contributes to the control of complex cognitive processes, we generated mice that express a form of WAVE-1 without the WRP binding sites (mWAVE-1). We find that these mWAVE-1 knock-in animals have reduced spine density and altered synaptic plasticity, in addition to specific deficits in memory retention. These studies show that WRP anchored to WAVE-1 plays a role in the control of cytoskeletal events that underlie normal neuronal development and synaptic plasticity.

\section{Materials and Methods}

\section{Gene targeting}

A bacterial artificial chromosome containing WAVE-1 (Incyte Genomics, St. Louis, MO) was used to subclone genomic DNA (gDNA) encompassing exons $3-8$ by bacterial recombineering as described previously (Liu et al., 2003). A neomycin cassette was inserted within the intron immediately upstream of exon 7 , again by bacterial recombineering. One of the homology arms for the neomycin targeting contained the mWAVE-1 mutations, thus simultaneously inserting the neomycin cassette and mutating exon 7. Correctly targeted embryonic stem (ES) cells were identified by PCR using primers within and outside of the gDNA contained in the targeting construct. Carryover of the mWAVE-1 mutations along with the neomycin cassette was confirmed by PCR cloning gDNA from targeted ES cells and sequencing. Chimeric mice were generated at the University of Cincinnati according to established protocols. Chimeric offspring were bred to C57BL/6 mice (The Jackson Laboratory, Bar Harbor, ME), establishing germ-line transmission, and bred further to $\mathrm{C} 57 \mathrm{BL} / 6$ mice for colony expansion.

\section{Animals}

All mice and rats were housed in the Vollum Institute and Oregon Health and Science University Animal Care Facility, and all procedures were approved by the Institutional Animal Care and Use Committee. Animals used for behavioral analysis ( $n=10$ for each genotype) were littermates from heterozygous mating pairs that had been backcrossed for two generations. Mice were housed individually during the behavioral testing, and the tests were administered in order of increasing stress levels.

\section{Behavioral tests}

The rotorod, anxiety tests, Morris water maze, and novel-object recognition tests were performed as described previously (Benice et al., 2006) and in brief below.

Morris water maze. Mice were trained with the platform clearly marked by a beacon (days 1 and 2; visible platform) and then trained with the beacon removed (days 3-5; hidden platform), during which the mice had to navigate by using spatial cues found throughout the room. Each day there were two sessions, $3.5 \mathrm{~h}$ apart, each consisting of three $60 \mathrm{~s}$ trials. Two hours after the second session of hidden platform training, the platform was removed and a probe trial was conducted. Mice were recorded during each trial with a Noldus Instrument Ethovision video tracking system (Noldus Information Technology, Sterling, VA).

Novel object recognition. For 3 consecutive days, the mice were individually habituated to a square open field $(16 \times 16$ inches; HamiltonKinder, Powa, CA) for $5 \mathrm{~min}$. On the fourth day, the mice were first trained in three consecutive $10 \mathrm{~min}$ familiarization trails with three plastic toy objects (one in each corner). Each mouse was then tested in (1) one novelty location trial in which one object was moved to a new location, and then in (2) an object novelty recognition trial in which one familiar object was replaced with a novel object. All objects and the arena were thoroughly cleaned with $5 \%$ acetic acid between trials to remove odors.

Cultured hippocampal neurons and quantitative image analysis Hippocampal neurons were prepared by two different methods. For transfection and quantification of spines (see Fig. $5 E-H$ ), hippocampal neurons were cultured from postnatal day 1-2 Sprague Dawley rats as described previously (Oh and Derkach, 2005). Transfections were performed on $8 \mathrm{~d}$ in vitro (DIV) neurons using Lipofectamine 2000 (Invitrogen, Carlsbad, CA). Four days later, the cells were fixed in $4 \%$ paraformaldehyde and 4\% sucrose in PBS, pH 7.4, and mounted in Prolong Antifade (Invitrogen).

For all other experiments, primary neuronal cultures were prepared from hippocampi of embryonic day 17.5 (E17.5) mice, as described previously (Banker, 1998). Genotyping of mouse embryos was done as described previously (Soderling et al., 2003). Dissociated neurons were plated onto poly-L-lysine-treated glass coverslips at a density of 25-50 cells $/ \mathrm{mm}^{2}$ and cocultured over a monolayer of astrocytes. Cells were maintained in Neurobasal medium (Invitrogen) supplemented with B27 and Glutamax. Plasmid DNA was introduced by electroporation using the Amaxa (Gaithersburg, MD) nucleofection protocol or using Lipofectamine 2000. Neurons were imaged on DIV1-DIV2 for growth cone analysis, on DIV5 for outgrowth measurements, or on DIV21 for visualization of immunostaining in spines. Digital images were collected using high-numerical aperture objectives and a MicroMax 1300YHS CCD camera (Roper Scientific, Tucson, AZ) mounted on a Leica (Bannockburn, IL) DM-RXA microscope or using a Yokogawa CSU-10 Nipkow Spinning Disk confocal head (Solamere Technologies, Salt Lake City, UT) and a Cascade 512B CCD camera (Roper Scientific) mounted on a Nikon (Tokyo, Japan) TE-2000 microscope. Quantitative analysis of total neurite outgrowth (sum of axon and dendrite lengths) and spine density from three independent experiments was performed using NIH Image $\mathrm{J}$ software. For morphology measurements in Figure $5 \mathrm{H}$, spine heads were defined as terminal enlargements that were at least twice the width of the spine shaft. Roundness measurements were made using Leica ASMDW software (Leica), and kymograph analysis was done using MetaMorph software (Molecular Devices, Downingtown, PA).

\section{Histology and spine density analysis}

Brains from three wild-type and three age-matched WAVE null adult mice were impregnated according to the Golgi procedure (RamonMoliner, 1970) using Rapid GolgiStain reagents (FD NeuroTechnologies, Ellicott City, MD), cut at $150 \mu \mathrm{m}$ with a cryostat, and mounted in Permount (Fisher Scientific, Pittsburgh, PA). Bright-field $z$-series images of apical dendrites from area CA1 of the hippocampus and layer 1 of the cortex were acquired using a CoolSnap HQ CCD camera (Roper Scientific) mounted on a Leica ASMDW. Representative images displayed are minimum projections from $z$-series stacks (see Figs. $2 L, M, 5 A, B$ ).

\section{Statistical analyses}

Statistical analyses were done using InStat from GraphPad Software (San Diego, CA). Statistical analysis of behavioral data were done using SPSS (SPSS, Chicago, IL). Assumptions of variance and normality were examined in all tests.

\section{Immunocytochemistry}

DIV21 neurons were fixed in 4\% paraformaldehyde and 4\% sucrose in PBS, $\mathrm{pH} 7.4$, for $15 \mathrm{~min}$ and permeabilized in $0.2 \%$ Triton X-100-PBS for $7 \mathrm{~min}$. Antibodies used for immunofluorescence were affinitypurified V059 (1:250) (Westphal et al., 2000) or VO101 (1:200) (Soderling et al., 2002) for WAVE-1, ArpC2 (1:100; Upstate, Charlottesville, VA), Arp3 (1:100; Upstate), and postsynaptic density 95 (PSD-95) (1: 100; Affinity BioReagents, Golden, CO). Tetramethylrhodamine isothiocyanate (TRITC)-phalloidin (1:200; Sigma, St. Louis, MO) was used to visualize filamentous actin (F-actin). For WAVE-1 and ArpC2 immunostaining, cells were subsequently incubated with biotin-conjugated secondary antibodies followed by fluorochrome-conjugated streptavidin (Jackson ImmunoResearch, West Grove, PA). To visualize PSD-95 immunostaining, neurons were incubated with fluorochrome-conjugated secondary antibodies after an overnight incubation in primary antibody. Stained cells were mounted in Prolong Antifade reagent (Invitrogen) and visualized on a Bio-Rad (Hercules, CA) MRC1024 laser-scanning confocal microscope. Representative images are from a single $z$ plane.

\section{Preparation of tissue and cell extracts}

Soluble tissue extracts were prepared by dounce homogenization in lysis buffer [25 mм HEPES, 150 mm NaCl, 0.5\% Triton X-100, 1 mм EDTA, 
and Complete protease cocktail (Roche Applied Science, Indianapolis, IN)] and centrifugation at $38,000 \times g$ for $1 \mathrm{~h}$ at $4^{\circ} \mathrm{C}$. Cell extracts were prepared by washing cells with PBS, followed by scraping adherent cells in $1 \mathrm{ml}$ of lysis buffer, incubating on ice for $15 \mathrm{~min}$, and then centrifuging at $15,000 \times g$ for $30 \mathrm{~min}$. Extracts were prepared from supernatants of each spin.

\section{Transfection of HEK-293 cells}

HEK-293 cells at $80 \%$ confluency were transfected using Lipofectamine 2000 (Invitrogen) according to the instructions of the manufacturer. Cells were harvested $24 \mathrm{~h}$ after transfection.

\section{PSD fractionation and immunoblot detection}

PSD fractions were prepared from frozen rat brains as described previously (Cho et al., 1992). Briefly, PSD fractions were separated by SDSPAGE on a $12 \%$ gel and electrotransferred to nitrocellulose membranes (Schleicher \& Schuell, Florham, NJ). Antibodies used were WAVE-1 (VO101), Arp3 (Upstate), ArpC2 (Upstate), PSD-95 (Upstate), and synaptosome-associated protein of $25 \mathrm{kDa}$ (SNAP-25) (Clontech, Palo Alto, CA).

\section{WAVE-1 immunoprecipitation and quantitative Western blot analysis}

Brain extracts from either wild-type or mWAVE knock-in mice (five of each genotype) were immunoprecipitated overnight with anti-WAVE antibody VO101. Immunoblot detection was done using anti-WRP antibody VO112 or anti-WAVE-1 monoclonal VO84. Multiplexing by infrared-labeled secondary antibodies (Invitrogen) and quantitative detection and analysis was done using the Odyssey imaging system (Li-Cor Biosciences, Lincoln, NE).

\section{Plasmids}

For all experiments in neurons, a vector using the chicken $\beta$-actin promoter (pBetaActin) was used to drive expression (Kaech et al., 1997). Plasmids encoding WAVE-1 were generated by PCR amplification of DNA and ligation of the restriction digested insert at sites downstream of enhanced green fluorescent protein (GFP) (Clontech). The WAVE-1 $444-559\left(\mathrm{R}_{512} \mathrm{~K}_{513} / \mathrm{EE}\right)$ actin binding mutant (Westphal et al., 2000) was subcloned into pBetaActin. Previous studies have shown these sequences of WAVE- 1 bind the Arp $2 / 3$ complex and that coordinated actin binding is required for stimulation of actin polymerization and branching (Rohatgi et al., 1999; Hufner et al., 2001). Thus, sequences that bind Arp2/3, but not actin, act as functional inhibitors of Arp2/3-mediated actin reorganization (Strasser et al., 2004). The coding region of $\gamma$-actin was ligated into the pBetaActin vector downstream of enhance yellow fluorescent protein (YFP) (Clontech) and used as a marker for dendritic spines. cDNA constructs for individual members of the WAVE- 1 complex were PCR cloned into the Gateway system (Invitrogen) from expressed sequence tags (American Type Culture Collection, Manassas, VA). All constructs were verified by sequencing.

\section{Hippocampal slice production}

Adult mice (8-16 weeks old) were anesthetized with pentobarbital (60 $\mathrm{mg} / \mathrm{kg}$, i.p.) and decapitated using procedures reviewed and approved by Institutional Animal Care and Use Committee at the Oregon Health and Science University. Brains were removed within 1 min of decapitation and immediately submerged in ice-cold, sucrose-modified artificial CSF (ACSF) for hippocampal dissection and slicing (in $\mathrm{mm}$ ): 110 sucrose, 60 $\mathrm{NaCl}, 2.5 \mathrm{KCl}, 28 \mathrm{NaHCO}_{3}, 1.25 \mathrm{NaH}_{3} \mathrm{PO}_{4}, 0.5 \mathrm{CaCl}_{2}, 7 \mathrm{MgCl}_{2}, 5$ glucose, and 0.6 sodium ascorbate, $\mathrm{pH} 7.4\left(\right.$ at $4^{\circ} \mathrm{C}$; presaturated by bubbling with $95 \% \mathrm{O}_{2} / 5 \% \mathrm{CO}_{2}$ at $21-22^{\circ} \mathrm{C}$ ). Hippocampal slices ( $400 \mu \mathrm{m}$, transverse) were prepared using a vibratome and an agar backing (2\%), and slices were recovered in warm ACSF (in mM): $125 \mathrm{NaCl}, 2.5 \mathrm{KCl}, 22.6$ $\mathrm{NaHCO}_{3}, 1.25 \mathrm{NaH}_{3} \mathrm{PO}_{4}, 2 \mathrm{CaCl}_{2}, 1 \mathrm{MgCl}_{2}$, and 11.1 glucose, $\mathrm{pH} 7.4$ (that was continuously saturated with $95 \% \mathrm{O}_{2} / 5 \% \mathrm{CO}_{2}$, for $30 \mathrm{~min}$ at $37^{\circ} \mathrm{C}$ ). Slices from the dorsal and ventral thirds of the hippocampus were discarded. After recovery, the holding chamber was equilibrated at 21$22^{\circ} \mathrm{C}$, and slices were held for $2-8 \mathrm{~h}$ before recording.

\section{Electrophysiology}

Submerged hippocampal slices were suspended in pairs on a nylon mesh in a small $(350-400 \mu \mathrm{l})$ recording chamber and perfused with ACSF at a rate of $2.5-3 \mathrm{ml} / \mathrm{min}$. The temperature in the recording chamber was raised and held at $32^{\circ} \mathrm{C}$ for the duration of the experiment. Synaptic responses were evoked by Schaffer collateral stimulation using a bipolar tungsten electrode (tip spacing, $140 \mu \mathrm{m}$; Frederick Haer Company, Bowdoinham, ME) and a $100 \mu$ s square wave test pulse (typically $30-40 \mu \mathrm{A}$ ) delivered at $60 \mathrm{~s}$ intervals. The stimulation intensity was adjusted to produce a basal field response of 1.2-1.4 mV. Field EPSPs (fEPSPs) were recorded with an ACSF-filled glass micropipettes (2-4M $\Omega$ ) placed in the stratum radiatum area of CA1 and connected via head stages to an A-M Systems (Carlsborg, WA) model 1800 amplifier. Signals were digitized at $100 \mathrm{kHz}$ using Molecular Devices (Palo Alto, CA) Digidata 1200 series interface running Clampex 8.0, and the initial slope of the fEPSPs was analyzed with Clampfit 8.0 software. NMDAR fEPSPs were pharmacologically isolated at basal field response intensity by blocking AMPA/ kainate receptors with $10 \mu \mathrm{M}$ CNQX (Tocris Cookson, Ballwin, MO) in the presence of low $\mathrm{Mg}^{2+}(0.1 \mathrm{~mm})$ in the recording chamber. The resultant NMDA receptors (NMDARs) fEPSPs were abolished in the presence of $50 \mu \mathrm{M}$ AP-5 (Tocris Cookson). Early-phase long-term potentiation (LTP) was induced using theta bursts: four pulses per burst (100 $\mathrm{Hz}$ ), five bursts per train $(5 \mathrm{~Hz})$, three trains (beginning $20 \mathrm{~s}$ apart). The late-phase LTP (L-LTP) was induced by four spaced applications of the above theta-burst protocol, at $5 \mathrm{~min}$ intervals. Long-term depression (LTD) was induced with low-frequency paired-pulse stimulation [900 paired pulses $(50 \mathrm{~ms}$ interstimulus interval [ISI]) delivered at $1 \mathrm{~Hz}$ ]. With the exception of the first data point after LTP/LTD induction, $3 \mathrm{~min}$ fEPSP averages are shown. The first data points after LTP/LTD induction were taken $20 \mathrm{~s}$ after the final stimulus. Slices from each genotype were balanced such that the average time in vitro was equal and the average age of animals were matched.

\section{Results}

\section{WAVE-1 regulates neurite outgrowth and growth cone dynamics}

The behavioral impairments detected in WAVE-1 null mice likely arise from the perturbation of signaling events that control cellular processes in the brain. Because Rac signaling regulates neurite outgrowth ( $\mathrm{Ng}$ et al., 2002), we reasoned that interruption of WAVE-1 signaling might alter neuronal growth cone dynamics. In support of this hypothesis, WAVE-1 was detected within the growth cones of early stage (day 2) cultured hippocampal neurons (Fig. 1A). Counterstaining for actin (Fig. $1 B$ ) emphasized an accumulation of WAVE-1 signal at the leading edge of lamellipodia and at the tips of filopodia (Fig. $1 A-C$ ). This finding confirms previous transfection experiments showing that a pool of WAVE-1-GFP concentrates within the growth cones of a neuroblastoma cell line (Nozumi et al., 2003).

To test whether WAVE-1 regulates neurite extension, hippocampal neurons from E18 embryos of WAVE-1 null $\left(\right.$ wave $\left.^{-/-}\right)$and wild-type (wave $e^{+/+}$) mice were transfected with GFP. Neurite outgrowth (the sum of axonal and dendrite length) was measured after $5 \mathrm{~d}$ in culture, a stage in which the majority of outgrowth is axonal (Fig. $1 D, E$ ). The extent of neurite outgrowth was $60.1 \%$ less $(n=92)$ in WAVE-1 knock-out neurons when compared with wild type (Fig. $1 F$ ). Analysis of fixed neurons stained for F-actin revealed that wave ${ }^{-/-}$growth cones appeared more "spiky" and elongated than wild-type growth cones (Fig. $1 G, H)$. These morphological differences were documented using a shape analysis algorithm (Kim and $\mathrm{Wu}, 1991)$ in which a perfect circle gives a roundness index of one. Increasingly irregular shapes are scored with higher roundness indices when analyzed with this algorithm (Fig. 1G,H, insets). Accordingly, wild-type growth cones had an average roundness index score of $4.3 \pm 0.31$ 

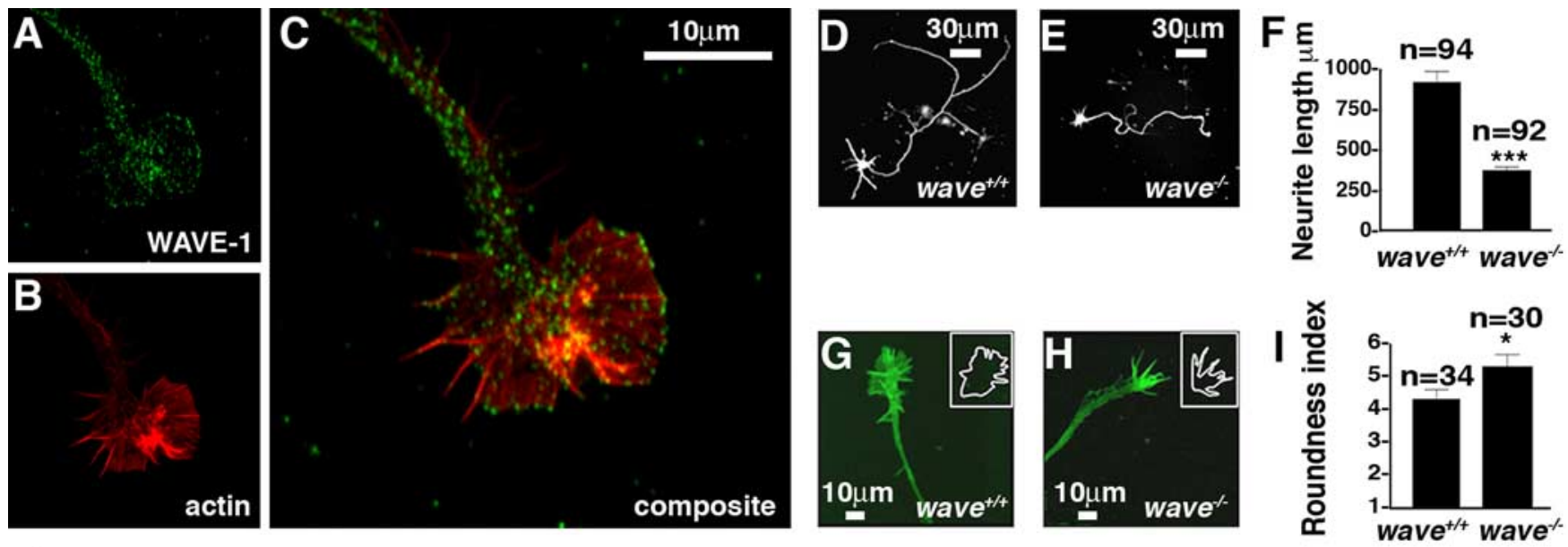

$\mathbf{J}$
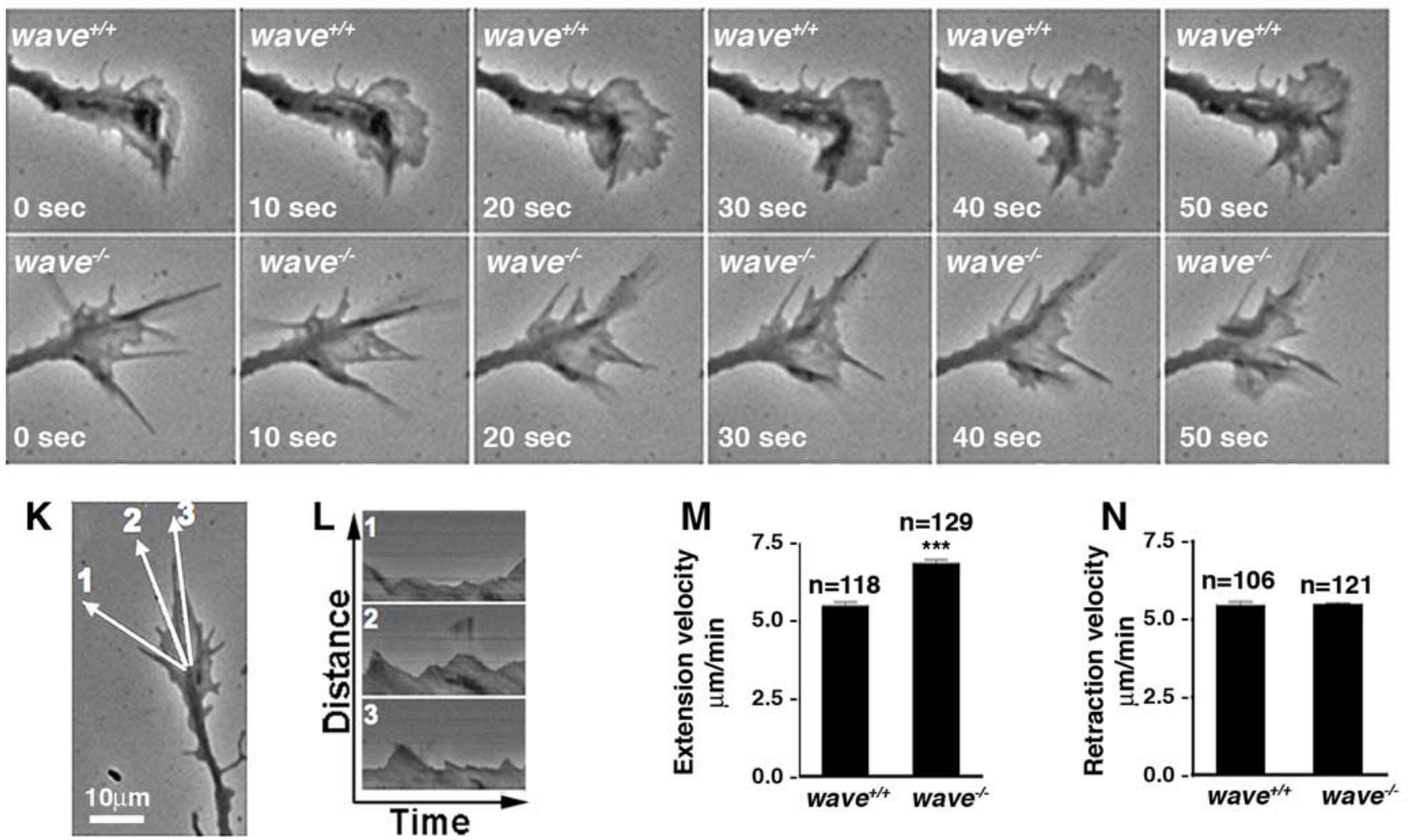

Figure 1. WAVE-1 participates in growth cone dynamics and neurite outgrowth of cultured hippocampal neurons. A-C, WAVE-1 is found in the growth cones of neonatal mouse cultured hippocampal neurons on day 2 in vitro. $\boldsymbol{A}$, WAVE-1 immunostaining; $\boldsymbol{B}$, TRITC-phalloidin-stained F-actin; $\boldsymbol{C}$, composite of $\boldsymbol{A}$ and $\boldsymbol{B}$. Hippocampal neurons transfected with GFP from wild-type (D) and WAVE-1 (E) null mice. $\boldsymbol{F}$, Neurite length (micrometers) was measured on day 5 in vitro, and the neurite outgrowth of wave ${ }^{+/+}(n=94)$ and wave ${ }^{-/-}(n=93)$ neurons was averaged ${ }^{* * *} p<$ 0.0001 using two-tailed unpaired $t$ test). Growth cones of wild-type $(\boldsymbol{G})$ and WAVE-1 $(\boldsymbol{H})$ null neurons were stained for F-actin with FITC-phalloidin. Insets in $\boldsymbol{G}$ and $\boldsymbol{H}$ are traces of the shape of each growth cone as revealed by fluorescence thresholding. $I$, Morphology assessment: roundness index was calculated for wave ${ }^{+/+}(n=34)$ and wave ${ }^{-/-}(n=30)$ growth cone shape traces $\left({ }^{*} p=\right.$ 0.039 using two-tailed unpaired $t$ test). $\boldsymbol{J}$, Phase-contrast images of wild-type (top) and WAVE-1 null (bottom) growth cones. Montage shows movement at 10 s intervals. $\boldsymbol{K}-\boldsymbol{N}$, Kymograph analysis of lamellipodial dynamics from wild-type and WAVE-1 null growth cones. $\boldsymbol{K}$, Representative image showing three lines of captured pixels from the origin to the periphery of the growth cone. $\boldsymbol{L}$, Kymograph of lines 1-3 in $\boldsymbol{K}$ showing lamellipodial extension and retraction events. Distance from the origin ( $y$-axis) and time ( $x$-axis) are labeled. The rate of extension and retraction of lamellipodia can be calculated from kymograph data. The extension velocity $(\boldsymbol{M})\left(\right.$ wave $^{+/+}, n=118 ;$ wave $\left.^{-/-}, n=129\right)$ and retraction velocity $(\boldsymbol{N})\left(\right.$ wave $^{+/+}, n=106 ;$ wave $\left.^{-/-}, n=121\right)$ from wild-type and WAVE-1 null growth cones $\left({ }^{* * *} p<0.001\right.$ using two-tailed unpaired $t$ test). Data $(\boldsymbol{F}, \boldsymbol{I}, \boldsymbol{M}, \boldsymbol{N})$ were collected from three independent culture preparations of neurons from each genotype. All data are presented as mean \pm SEM.

$(n=34)$, whereas wave ${ }^{-/-}$growth cones exhibited an average roundness index of $5.3 \pm 0.38(n=30)$ (Fig. $1 I)$.

Live-cell imaging of cultured hippocampal neurons provided additional information about growth cone dynamics. In these experiments, the leading edge of the knock-out growth cones rarely extended to the tips of the filopodia, suggesting defects in the lamellipodia (Fig. 1J) (supplemental Movie S1, available at www.jneurosci.org as supplemental material). This was confirmed by kymograph analysis in which lamellipodial movement was measured by extracting a line of pixels along the axis of motility (Fig. $1 K$, lines $1-3$ ). When lines of pixels from successive frames of a time-lapse sequence are pasted side by side, it generates a record of the dynamic nature of lamellipodial movement (Hinz et al., 1999). Using this approach, we were able to show that 


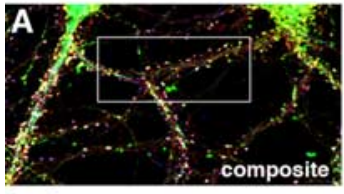

Inset:
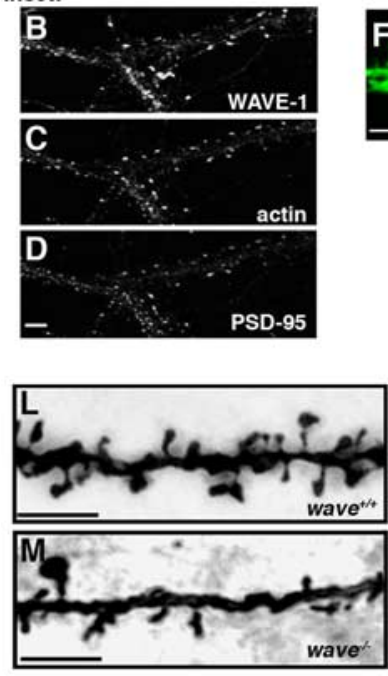
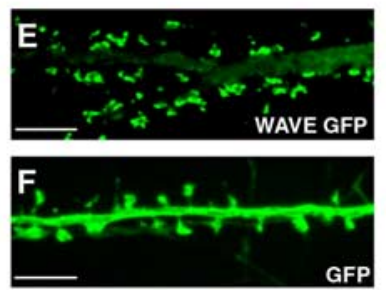

GFP

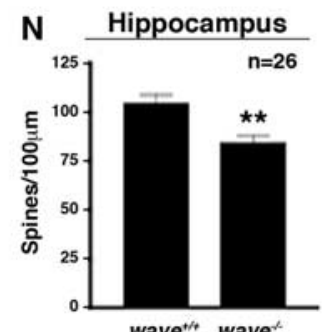

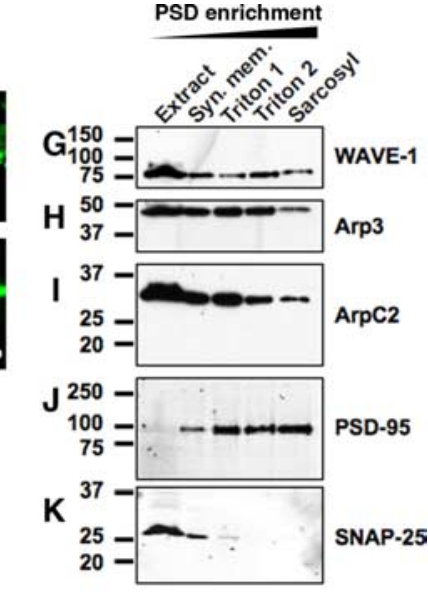

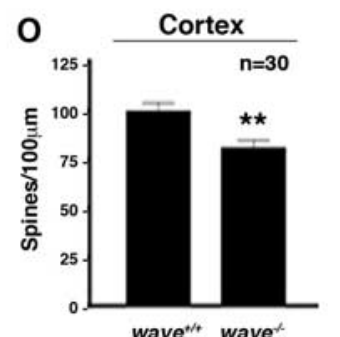

Figure 2. WAVE-1 is localized to spines and regulates spine density. $\boldsymbol{A}$, Composite image of $21 \mathrm{~d}$ in vitro cultured wild-type hippocampal neurons immunostained for WAVE-1 (green), F-actin (red), and PSD-95 (blue) subcellular location. $\boldsymbol{B}-\boldsymbol{D}$, Enlargement of the inset region shown in $\boldsymbol{A}$. $\boldsymbol{B}$, WAVE-1 immunostaining; $\boldsymbol{C}$, Texas Red-phalloidin staining of F-actin; $\boldsymbol{D}$, PSD-95 immunostaining. Fluorescence image of a section of dendrite showing the subcellular location of WAVE-1 GFP $(\boldsymbol{E})$ and GFP control $(\boldsymbol{F})$ in $21 \mathrm{~d}$ in vitro cultured wild-type hippocampal neurons. WAVE-1-GFP is found primarily in spine heads and to a lesser extent in the shaft and dendrite, whereas soluble GFP is more evenly distributed in all of the dendritic structures. G-K, Postsynaptic density enrichment from rat brain extracts. Immunoblot detection of WAVE-1 (G), Arp3 (H), ArpC2 (I), PSD-95 (J), and SNAP-25 (K) in extracts and detergent-soluble PSD fractions. WAVE-1, the Arp2/3 complex subunits Arp3 and ArpC2, and PSD-95 are present within the core PSD (sarcosyl) fraction. The presynaptic protein SNAP-25 is present in the synaptic membrane fraction (Syn. mem.). $\boldsymbol{L}-\mathbf{0}$, Golgi-impregnated hippocampal sections show dendritic spines in neurons from wild-type $(\boldsymbol{L})$ and WAVE-1 ( $\boldsymbol{M})$ null mice. Quantification of spine density (spines/100 $\mu \mathrm{m}$ ) in dendritic segments from the hippocampus ( $N$ ) (area CA1; $n=26$; ${ }^{* *} p=0.0026$ using two-tailed unpaired $t$ test) and cortex (0) (layer $1 ; n=30 ;{ }^{* *} p=0.0027$ using two-tailed unpaired $t$ test).

wave $^{-/-}$lamellipodia extended at a rate of $6.85 \pm 0.13 \mu \mathrm{m} / \mathrm{min}$ $(n=118)$ (Fig. $1 M)$. This is significantly faster than the rate of wave $^{+/+}$lamellipodial extension $(5.48 \pm 0.14 \mu \mathrm{m} / \mathrm{min} ; n=129)$ (Fig. 1M). Surprisingly, the retraction velocity of lamellipodia was similar in both genotypes (Fig. $1 N$ ). Collectively, all of the data in Figure 1 suggest that the loss of WAVE-1 affects both lamellipodial dynamics and the pattern of growth cone motility in a manner that retards neurite extension in cultured neurons.

WAVE-1 plays a role in the development of dendritic spines Subsequent to neurite extension is the formation of excitatory synaptic connections, which are dependent on the development of actin-rich dendritic spines (Carlisle and Kennedy, 2005). Immunostaining of WAVE-1 in late-stage (day 21) hippocampal neurons (Fig. $2 A, B$ ) and counterstaining with F-actin and the postsynaptic marker PSD-95 (Fig. $2 B-D$ ) demonstrated the presence and enrichment of this anchoring protein in dendritic spines. Additional experiments using GFP-tagged WAVE-1 confirmed the concentrated localization and targeting of WAVE-1 to spines (Fig. $2 E, F$ ). WAVE-1 did not fill the spine but was localized to subregions within the spine head (Fig. 2E). Additional coexpression experiments were performed with WAVE-1 GFP and tomato fluorescent protein as a marker for dendritic morphology. These studies confirmed that dendritic morphology was normal and that the scaffolding protein was localized to specific regions of the spine head (S. H. Soderling and J. D. Scott, unpublished observation). Parallel immunostaining experiments also detected the ArpC2 subunit of the Arp2/3 complex within dendritic spines (data not shown). Finally, these findings were substantiated with biochemical evidence when each protein was identified in postsynaptic density fractions isolated from rat brain (Fig. $2 G-K$ ). Thus, WAVE- 1 is targeted to the dendritic spines of mature hippocampal neurons.

The concentration of WAVE-1 in spines suggested that it might regulate spine development or function in vivo. Tissue sections from both the CA1 region of the hippocampus and layer 1 of the cortex of 10-week-old mice were stained using Golgi impregnation. Quantitative image analysis of dendrites revealed a reduction in spine density in the WAVE-1 null samples (hippocampus: wave ${ }^{+/+}$, $104 \pm 5$ spines/ $100 \mu \mathrm{m}$; wave ${ }^{-/-}, 83 \pm 4$ spines/100 $\mu \mathrm{m} ; p<0.01$; cortex: wave ${ }^{+/+}$, $99 \pm 4.5$ spines/100 $\mu \mathrm{m}$; wave ${ }^{-/-}, 79.8 \pm$ $4 ; p<0.01$ spines $/ 100 \mu \mathrm{m}$ ) (Fig. $2 L-O$ ).

\section{Loss of WAVE-1 alters \\ synaptic plasticity}

Recent evidence suggests that actin remodeling within dendritic spines influences synaptic transmission (Fukazawa et al., 2003; Okamoto et al., 2004). Electrophysiological analysis of hippocampal slices (area CA1) from WAVE-1 null mice detected differences in synaptic transmission. First, the loss of WAVE-1 resulted in a $29 \%$ reduction in the maximal fEPSPs ( $p=0.0014$ at highest stimulus intensity using two-tailed unpaired $t$ test) (Fig. $3 A$ ). Second, the early phase of postsynaptic LTP was increased in the WAVE- 1 knock-out mice $(p<0.0001$ using unpaired two-tailed $t$ test for responses from 0 to $60 \mathrm{~min}$ ) (Fig. $3 B$ ). In contrast, these mice exhibited reduced LTD ( $p=$ 0.001 using unpaired two-tailed $t$ test for responses $0-60 \mathrm{~min}$ ) (Fig. 3C). The increase in LTP magnitude was not restricted to the early-phase LTP. In mice lacking WAVE-1, L-LTP, induced by repeated theta bursts, resulted in a modest increase in potentiation at $150-180 \mathrm{~min}(p<0.0001$ using unpaired two-tailed $t$ test for responses 150-180 min) (Fig. 3D). NMDAR activity responses were quantified for each genotype because this ion channel contributes to the induction of both LTP and LTD. Interestingly, the NMDAR to AMPA receptor (AMPAR) fEPSP ratio was significantly higher in the absence of WAVE-1 ( $p=0.02$ by unpaired two-tailed $t$ test) (Fig. 3E). In summary, these data show that loss of WAVE-1 impacts molecular mechanisms of synaptic plasticity that may underlie some of the behavioral abnormalities observed previously in the wave ${ }^{-/-}$mice (Soderling et al., 2003). However, it was unclear which components of the WAVE-1 signaling complex contributed to these aberrant phenotypes. Certainly, WRP could be a contributing factor because this GAP protein likely promotes tight regulation of actin-remodeling events by directly anchoring to WAVE-1. In addition, haploin- 
sufficiency of WRP has been linked to a form of human mental retardation called 3p-syndrome (Endris et al., 2002).

Generation of mutant WAVE-1 mice $\left(\boldsymbol{w a v e} \boldsymbol{e}^{m / m}\right)$

To ascertain whether perturbation of the WAVE-WRP interaction contributes to the pathophysiology of the WAVE-1 null animals, knock-in mice ( wave $e^{m / m}$ ) with reduced WRP binding properties were generated. We have shown previously that the $\mathrm{SH} 3$ domain of WRP binds to proline-rich sequences between amino acids 322-332 and 425-431 of WAVE-1 (Soderling et al., 2003). A deleted form of the scaffolding protein (called mWAVE-1) that lacked both of these sites was engineered and expressed in HEK-293 cells (Fig. 4A, bottom, lane 3 ). This mutant scaffolding protein exhibited a reduced ability to bind WRP as assessed by immunoblot analysis of WAVE immunoprecipitates (Fig. 4A, top, lanes 2 and 3 ). In contrast, additional immunoblot analysis confirmed that other WAVE binding partners, including HSPC300, Abl interacting protein 1 (Abi1), Abl, PKA RII, actin, and the Arp $2 / 3$ complex, retained their full ability to bind to mWAVE-1 (supplemental Fig. S2, available at www.jneurosci.org as supplemental material). A trace of WRP was consistently coimmunoprecipitated with mWAVE-1 (Fig. 4A, top, lane 3). Thus, we concluded that WRP might have a secondary site of interaction through its association with other members of the signaling complex. Additional coimmunoprecipitation experiments identified Abi-1 as a likely WRP binding partner (supplemental Fig. S3, available at www.jneurosci.org as supplemental material). In summary, the above experiments demonstrate that mWAVE-1 forms a functional signaling complex, yet with substantially reduced levels of WRP.

A targeting vector that engineered these mutations (deletion of residues 322-332 and 425-431) into exon 7 of the WAVE-1 gene was constructed using the bacterial recombineering method (Fig. 4B) (Liu et al., 2003). ES cells expressing this targeting construct were selected, and PCR screening was used to confirm homologous recombination. Exon 7 from the targeted allele was PCR cloned and sequenced to verify that both mutations were present (Fig. 4C,D). Embryonic stem cell lines positive for these mutations in exon 7 (Fig. $4 E$ ) were used to generate mice homozygous for the mutation $\left(\right.$ wave $\left.e^{m / m}\right)$. The resultant wave $e^{m / m}$ mice appeared healthy and were indistinguishable from wildtype $\left(\right.$ wave $^{+/+}$) littermates (Fig. $\left.4 F\right)$. Immunoprecipitation with WAVE-1 antibody showed that the expression levels of the mutant and wild-type proteins were similar in brain extracts (Fig. $4 G$, bottom). However, the amount of WRP associated with mWAVE- 1 was reduced $45.75 \%(n=5)$ when compared with the amount coprecipitating with wild-type WAVE-1 (Fig. 4G, top,
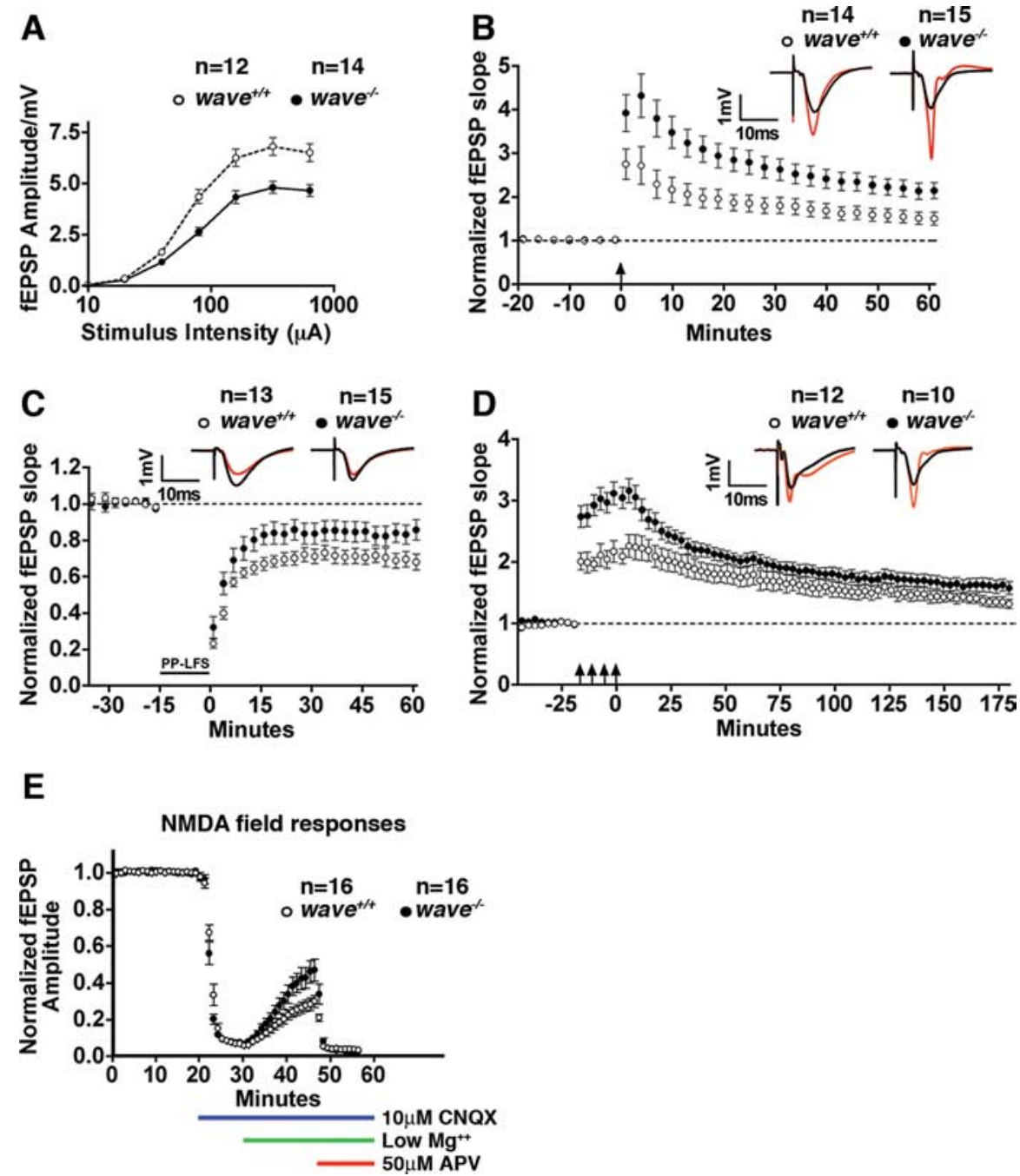

Figure 3. WAVE-1 regulates synaptic plasticity. Electrophysiological analysis of hippocampal slices from wild type $\left(\right.$ wave $\left.^{+/+}\right)$ and WAVE-1 null (wave ${ }^{-\prime-}$ ) mice. $A$, Graph depicting the synaptic input- output relationship (semi-log scale). Data represent mean $\pm S E M ; ~ n$ values are shown. $B$, Graph comparing LTP induced by three trains of theta-burst stimulation [arrow; 4 pulses/ ( 900 paired pulses $(50 \mathrm{~ms} \mathrm{ISI})$ delivered at $1 \mathrm{~Hz}$. Representative traces before (black) and $60 \mathrm{~min}$ after (red) induction of LTD. ) and $180 \mathrm{~min}$ after (red) induction of LTP. Data represent mean \pm SEM; $n$ values are shown. $E$, Graph comparing normalized NMDAR field responses induced by Schaffer collateral stimulation at basal intensity in the presence of CNQX/low $\mathrm{Mg}^{2+}$ (see Materials and Methods). Data represent mean $\pm \mathrm{SEM} ; n$ values are shown.

$H)$. Consequently, the wave $e^{m / m}$ mice provided a model system to test the functional consequences of reduced WRP interaction with the WAVE-1 signaling complex.

\section{Characterization of mWAVE-1 mice}

Coronal brain sections from wave $e^{m / m}$ mice appeared to be normal with gross structures that were well formed (data not shown). However, given the impairments in spine development observed in the WAVE-1 null mice, we embarked on a morphological analysis of wave $e^{m / m}$ neurons. Using Golgi impregnation, we measured spine density in tissue sections from the hippocampus (CA1) and cortex (layer 1) of 10-week-old wave $e^{\mathrm{m} / \mathrm{m}}$ and wave $e^{+/+}$ mice (Fig. 5A, B). The knock-in mice had a significant reduction in spine density in sections from both of these brain regions (hippocampus: wave ${ }^{+/+}, 103 \pm 5.9$ spines $/ 100 \mu \mathrm{m} ;$ wave $^{m / m}$, 


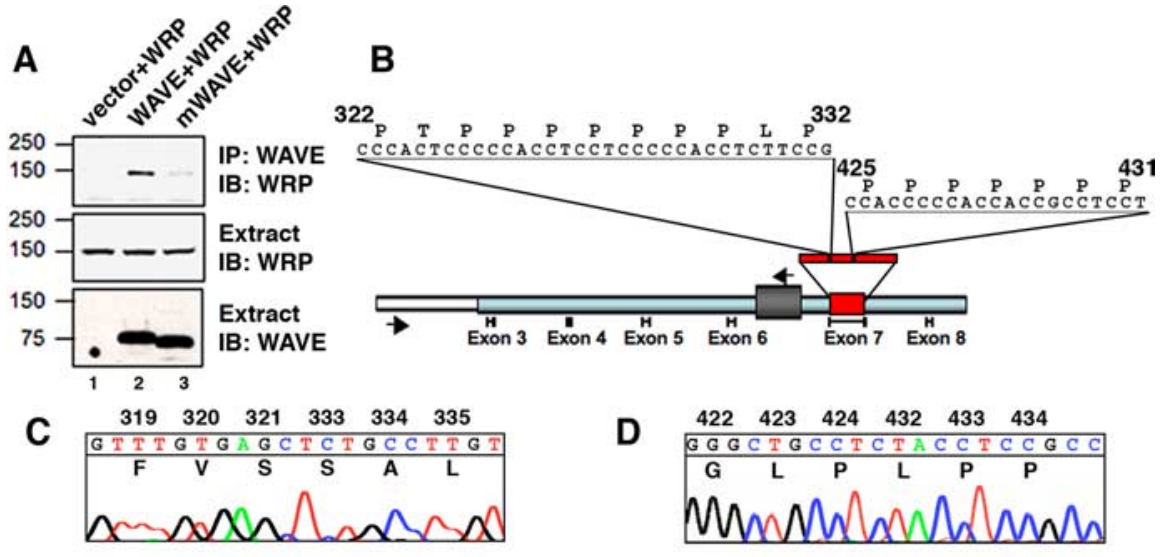

E

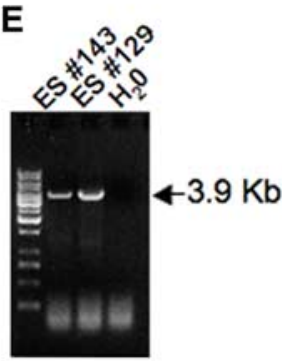

$\mathbf{F}$

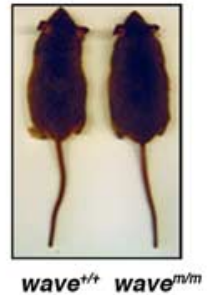

G
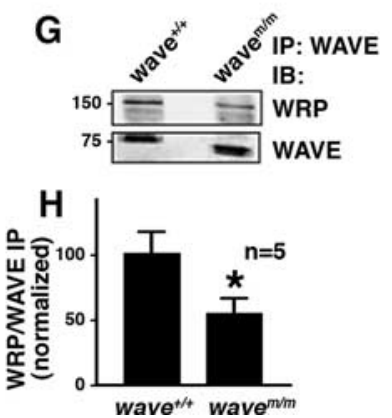

Figure 4. wave $^{m / m}$ mice lack WRP binding sites and exhibit reduced WRP association in vivo. A, Western blot analysis of WRP in WAVE-1 immunoprecipitations (IP) from HEK-293 extracts expressing WRP alone, WRP and WAVE-1, or WRP and WAVE-1 lacking amino acids 322-332 and 425-431 (mWAVE). Immunoblots (IB) detecting WRP in WAVE immunoprecipitations (top), WRP in total extracts (middle), and WAVE in total extracts (bottom). B, Schematic of targeting construct used to introduce mWAVE mutations into the WAVE-1 locus. Relative positions of exons are indicated below. Light blue box indicates genomic region used in targeting construct, and white-boxed region represents flanking genomic sequence outside of the targeting construct. Gray box between exon 6 and exon 7 indicates insertion of neomycin resistance, and red box represents exon 7 in which the mutations were introduced. Arrows indicate position of primers used to screen embryonic stem cells for homologous recombination. Sequence above exon 7 represents the sequences deleted. $\boldsymbol{C}, \boldsymbol{D}$, Chromatogram of sequence data from targeted embryonic stem cells demonstrating the sequence deletions from homologous recombination. Amino acid sequence and residue number are indicated above the nucleotide sequence. $E$, Agarose gel of embryonic stem cell PCR screen for homologous recombination. Two positive lines, ES \#143 and ES \#129, are indicated along with a negative control $\left(\mathrm{H}_{2} 0\right)$. $\boldsymbol{F}$, Wild-type $\left(\right.$ wave $\left.e^{+/+}\right)$and knock-in $\left(\right.$wave $\left.e^{m / m}\right)$ mice at 14 weeks of age. $\mathbf{G}$, WAVE-1 immunoprecipitations from brain extracts of wild-type versus knock-in mice. Top is an immunoblot of coprecipitated WRP. Bottom is an immunoblot of WAVE-1. H, Quantitation of the amount of WRP coprecipitated with either WAVE or mWAVE from wild-type or knock-in brain extracts. Ratio is the amount of WRP divided by the amount of WAVE present in each immunoprecipitation ( $n=5 ;{ }^{*} p=0.036$ using one-tailed unpaired $t$ test).

$88 \pm 4$ spines $/ 100 \mu \mathrm{m} ; p<0.05$, cortex: wave $^{+/+}, 91 \pm 4.7$ spines $/ 100 \mu \mathrm{m} ;$ wave $^{m / m}, 68.4 \pm 5$ spines $/ 100 \mu \mathrm{m} ; p<0.01$ ) (Fig. $5 C, D)$. Thus, WRP anchoring contributes to WAVE-1-mediated control of neuronal spinogenesis. Based on our results, our working hypothesis was that disruption of WAVE-1 signaling would interrupt the transduction of signals to Arp2/3 in spines. Accordingly, expression of a dominant interfering mutant (WAVE-1 444-559, $\mathrm{R}_{512} \mathrm{~K}_{513} / \mathrm{EE}$ ) that competes for activation of Arp2/3 (Westphal et al., 2000; Strasser et al., 2004) reduced spine density in cultured neurons by $29 \%$ (control, $44.60 \pm 3$ spines $/ 100 \mu \mathrm{m}$; WAVE-1 444-559EE, $32.18 \pm 3$ spines $/ 100 \mu \mathrm{m} ; p<0.01$ ) (Fig. $5 E-G)$. Because the shape of spines is also dependent on actin remodeling, we also examined their morphology in these experiments. Interestingly, dendritic spines in WAVE-1 444-559EEtransfected neurons also adopted a more filopodial morphology (1.5-fold reduction in head/filopodial ratio; control, $2.52 \pm 0.3$; WAVE-1 444-559EE, $1.72 \pm 0.2 ; p<0.01$ ) (Fig. $5 H$ ). These experiments imply that WAVE-1 signaling to the actin cytoskeleton regulates aspects of both neuronal spinogenesis and spine morphology.
A subset of the electrophysiological changes in the CA1 region of the hippocampus that we measured in the WAVE-1 null $\left(\right.$ wave $\left.^{-/-}\right)$mice was also detected in the mWAVE mutant mice. In the wave $^{m / m}$ mice, the maximal fEPSP was also reduced, particularly at higher stimulus intensities $[p=0.0184$ at highest stimulus intensity $(640 \mathrm{~mA})$ using a two-tailed $t$ test] (Fig. 6A). However, early-phase LTP and LTD in mWAVE-1 knock-in mice were normal (Fig. $6 B, C$ ). Nonetheless, the wave $^{m / m}$ mice exhibited increased L-LTP in a manner similar to the WAVE-1 null mice $(p<0.0001$ using unpaired twotailed $t$ test for responses $150-180 \mathrm{~min}$ ) (Fig. 6D). Paired-pulse facilitation was normal in both animal models, which is consistent with the postsynaptic localization of WAVE-1 and suggests that neurotransmitter release probability is not regulated by the signaling scaffold (supplemental Fig. S4, available at www. jneurosci.org as supplemental material). Although WAVE-1 knock-out and mWAVE-1 knock-in mice both exhibit increased LTP, they were not electrophysiologically equivalent. Early-phase LTP and L-LTP were both increased in WAVE-1 null animals, whereas the mWAVE-1 knock-in mice were limited to a specific enhancement of L-LTP. These differences led us to examine whether there were behavioral differences in these two mouse models consistent with these findings.

\section{wave $^{m / m}$ mice exhibit impairment in memory retention}

Behavioral tests were conducted on wave $^{m / m}$, wave $e^{m /+}$, and wave ${ }^{+/+}$mice as described previously (Soderling et al., 2003). All three genotypes tested comparably for measures of sensorimotor function and anxiety (data not shown). However, wave $e^{m / m}$ mice were impaired in their memory retention as assessed by the Morris water maze to evaluate hippocampal-dependent spatial learning and memory (Morris et al., 1982). Initially, mice were trained for four sessions (two sessions a day) to swim to a visible platform (cued training). During sessions 5-10, the latency of mice to swim to a submerged hidden platform was measured (acquisition). Mice from each genotype performed equally well in the cued and the acquisition training (Fig. 7A) and had no differences in swim speed (data not shown). Two hours after sessions 6,8 , and 10 , the hidden platform was removed and spatial-memory retention (probe trials) was assessed. Wild-type and heterozygous mice preferentially searched in the target quadrant in all probe trials (after sessions 6, 8, and 10) (Fig. 7B-D). In contrast, wave $e^{m / m}$ mice failed to spend significantly more time searching in the target versus nontarget quadrants during sessions 6 and 8 of the probe trials (Fig. 7 B, C, Day 3 and Day 4 Probe). However, after 1 additional day of training (after 10 sessions), the $\mathrm{wave}^{\mathrm{m} / \mathrm{m}}$ mice were able to distinguish between the target and nontarget quadrants (Fig. 7D). Thus, mice expressing mWAVE have impaired 
memory retention but with additional training are able to overcome this impairment. An additional probe trial performed $14 \mathrm{~d}$ after the last day of hidden platform training assessed the stability of memory retention in these mice. The wave $e^{m / m}$ mice lost spatial memory in contrast to the two other genotypes, which retained the ability to identify the target quadrant versus all other quadrants (Fig. $7 E, F$ ). These data show that the wave $e^{m / m}$ mice not only require more training to retain spatial memory but, once this memory is formed, it is also less stable. The specific impairment of spatial memory retention in the wave $e^{\mathrm{m} / \mathrm{m}}$ mice is consistent with the normal hippocampal early-phase LTP and altered L-LTP observed in these mice.

This memory impairment was not restricted to spatial-based tests. Cognitive

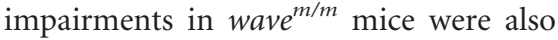
observed in novel-object recognition tests to evaluate hippocampal-independent nonspatial memory. For 3 consecutive days, mice were habituated to an enclosure, and, on the fourth day, they were subjected to three consecutive familiarization trials with three individual objects. After the familiarization trials, the mice were tested for novelty location, in which one familiar object was moved to a new location and novelty recognition in which one familiar object was replaced by a novel object. No differences were observed in the novel location trials (data not shown). wave $^{m / m}$ mice did, however, spend significantly less time exploring the novel object when compared with their wild-type littermates (Fig. 7G). Together, the above results suggest that WAVE-1-WRP interaction is indeed necessary for aspects of both spatial and nonspatial memory.

\section{Discussion}

Spatiotemporal control of smallmolecular-weight GTPase action involves two classes of effector proteins: guanine nucleotide exchange factors (GEFs) that stimulate their activity and GAPs that suppress G-protein signaling. Biochemical and genomic analyses have identified a plethora of GEF and GAP proteins that service the 20 or so members of the Rho GTPase family (Moon and Zheng, 2003). For example, 70 human Rho GAP proteins terminate Rho GTPase signaling events in a variety of cellular contexts. How specificity is achieved between individual GAPs and GTPases is still unclear. We have shown previously that WRP functions as a WAVE-1-associated Rac GAP that terminates Rac signaling in neurons (Soderling et al., 2002). In this report, we demonstrate that a reduction in the amount of WRP interacting with WAVE-1 affects the dendritic
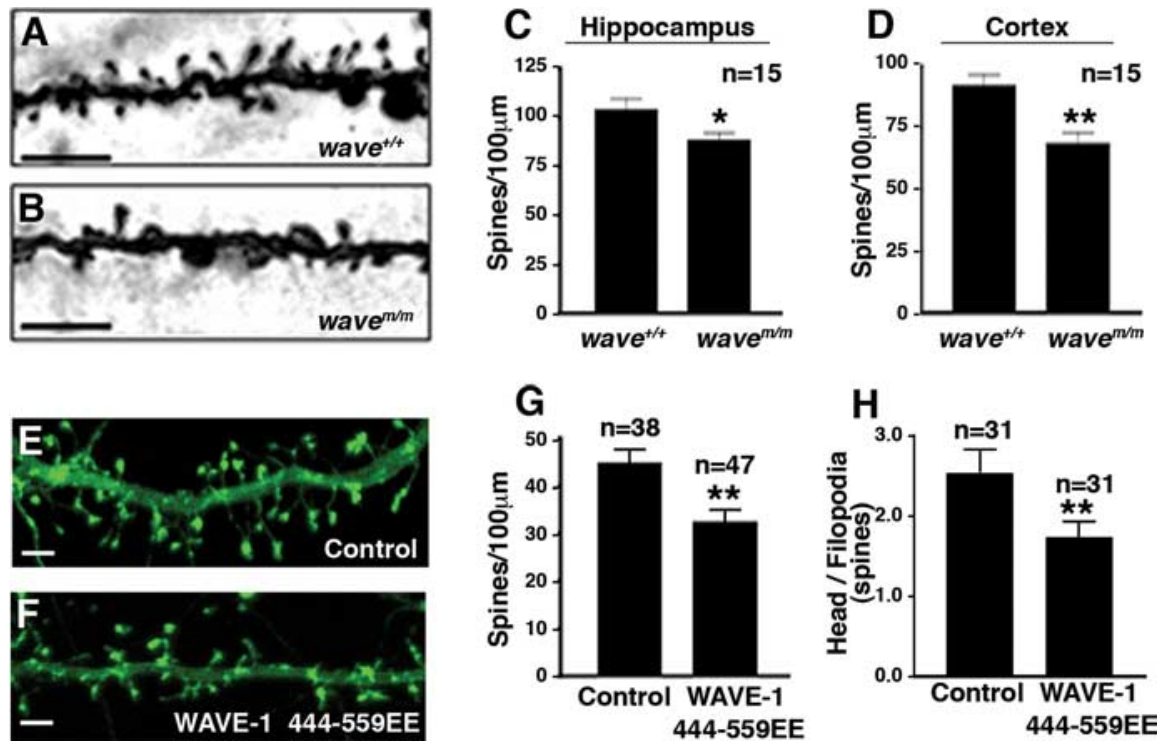

Figure 5. Anchored WRP regulates spine density via WAVE-1 and Arp2/3. Hippocampal sections of wild-type $(\boldsymbol{A})$ and $m W A V E$ knock-in $(\boldsymbol{B})$ mice after Golgi impregnation show dendritic segments of neurons. Quantitation of spine density (spines/100 $\mu \mathrm{m})$ from hippocampus $\left(\boldsymbol{C}\right.$; area $(A 1)\left({ }^{*} p=0.0375\right.$ using two-tailed unpaired $t$ test) and cortex (D; layer 1$)\left({ }^{* *} p=0.0015\right.$ using two-tailed unpaired $t$ test). $\boldsymbol{E}, \boldsymbol{F}$, Fluorescence image of a section of dendrite showing the spine density in cultured hippocampal neurons expressing either YFP-actin (E) or WAVE-1444-559EE and YFP-actin (F). G, Quantification of spine density (spines/100 $\mu \mathrm{m})\left({ }^{* *} p=0.0027\right.$ using two-tailed unpaired $t$ test). $\boldsymbol{H}$, Quantification of spine morphology (ratio of spines with heads/ filopodial spines) $\left({ }^{* *} p=0.033\right.$ using two-tailed unpaired $t$ test). All data are presented as mean \pm SEM. Scale bars, $5 \mu \mathrm{m}$.
A
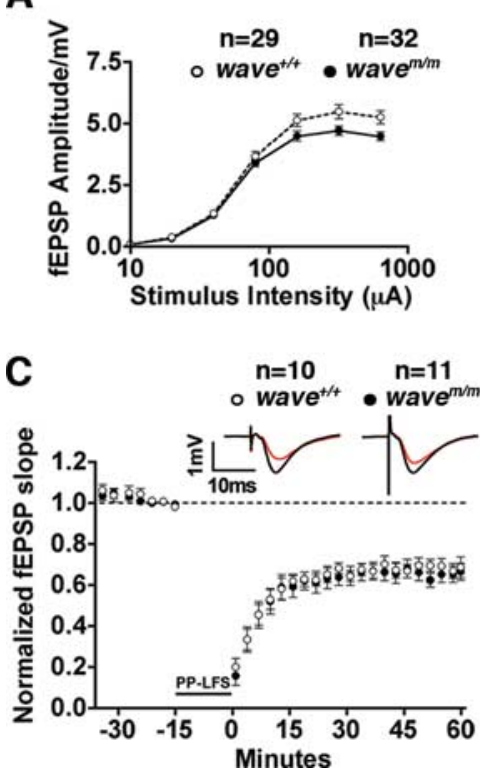

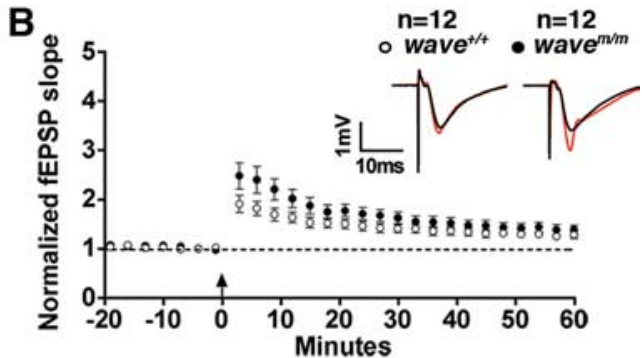

D

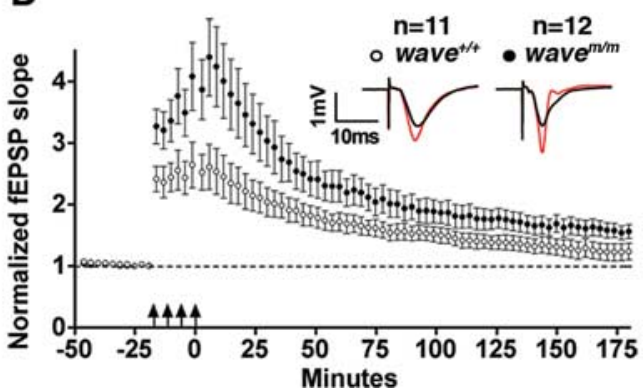

Figure 6. Enhanced L-LTP in the wave $e^{m / m}$ mice. $\boldsymbol{A}-\boldsymbol{D}$, Electrophysiological analysis of hippocampal slices from wild-type and mWAVE knock-in mice. $\boldsymbol{A}$, Graph comparing the synaptic input-output relationship over a range of stimulus intensity (semi-log scale). Data represent mean \pm SEM; $n$ values are indicated. $\boldsymbol{B}$, Graph comparing LTP induced by three trains of theta-burst stimulation [arrow; 4 pulses/burst ( $100 \mathrm{~Hz}$ ), 5 bursts/train $(5 \mathrm{~Hz}), 3$ trains (20 sapart)]. Representative traces before (black) and 60 min after (red) induction of LTP. Data represent mean \pm SEM; $n$ values are indicated. $C$, Graph comparing LTD induced by low-frequency paired-pulse stimulation [ 900 paired pulses $(50 \mathrm{~ms} \mathrm{ISI}$ ) delivered at $1 \mathrm{~Hz}$ ]. Representative traces before (black) and 60 min after (red) induction of LTD. Data represent mean \pm SEM; $n$ values are indicated. $D$, Graph comparing L-LTP induced by four epochs of theta-burst trains [arrows; 4 pulses/burst (100Hz), 5 bursts/train ( $5 \mathrm{~Hz}), 4$ trains ( 5 min apart)]. Representative traces before (black) and 180 min after (red) induction of LTP. Data represent mean $\pm S E M ; n$ values are indicated.

morphology of neurons, their synaptic transmission, and promotes subtle but measurable behavioral changes in the mutant mice. Our biochemical characterization of the wave ${ }^{m / m}$ mice indicates that direct interaction with WAVE-1 accounts for $\sim 50 \%$ 

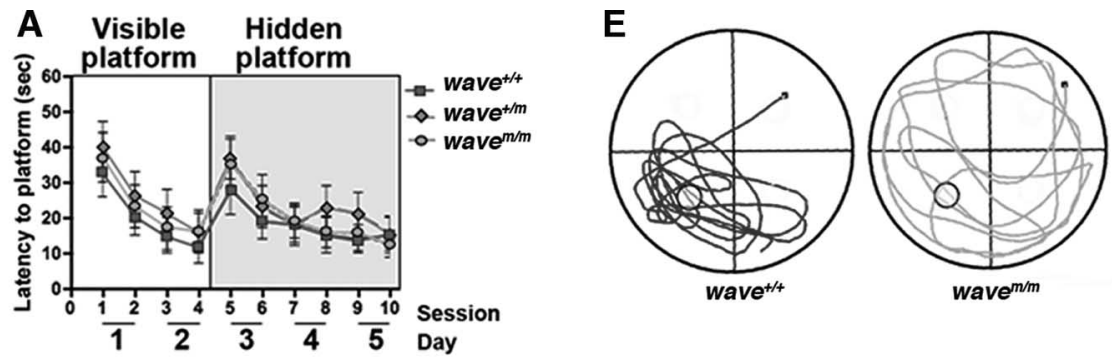

B
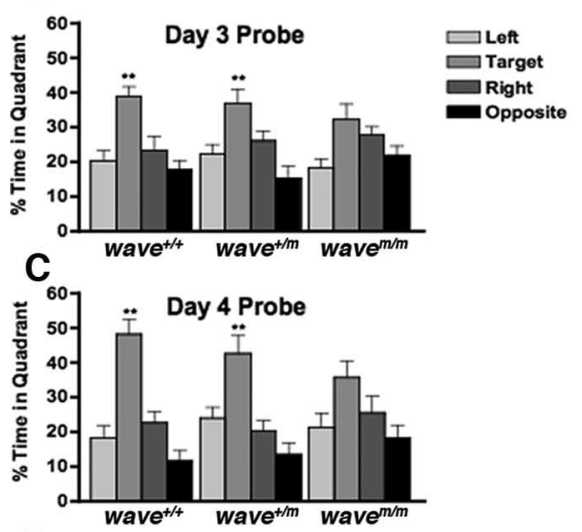

$\mathbf{F}$

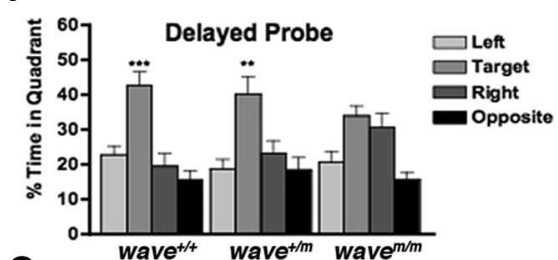

G

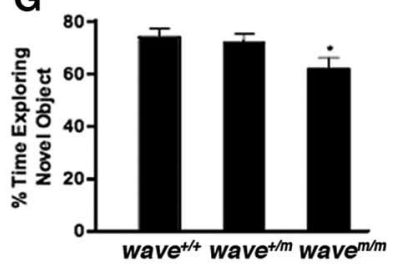

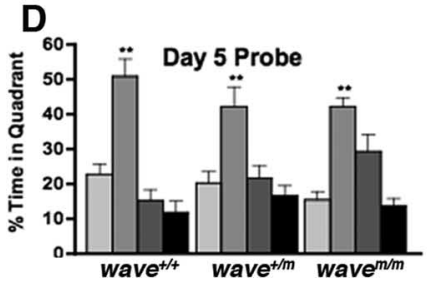

Figure 7. Disruption of WRP anchoring to WAVE affects memory retention. $\boldsymbol{A}-\boldsymbol{F}$, Analysis of spatial learning and memory performance of wild-type (wave $\left.{ }^{+/+}\right)$, heterozygous $\left(\right.$wave $\left.e^{+/ m}\right)$, and knock-in $\left(\right.$ wave $\left.e^{m / m}\right)$ mice in the Morris water maze $(n=10$ each genotype; mean \pm SEM value is shown). $A$, Time to swim to the platform (latency) was measured for wild-type (squares), heterozygous (diamonds), and knock-in (circles) mice. The mice were tested in two daily sessions of three trials each. Sessions 1-4 are learning trials for the visible platform, and sessions 5-10 are learning trials for the hidden (submerged) platform. No significant differences were observed in the learning curves. $\boldsymbol{B}-\boldsymbol{F}$, Memory retention after learning trials was measured in probe trials (platform removed). The percentage of time spent searching in the target quadrant (quadrant containing platform during sessions 5-10) versus nontarget quadrants was measured. ${ }^{* *} p<0.01$ target versus any other quadrant using one-way ANOVA. Probe trials were conducted $2 \mathrm{~h}$ after session 6 on day $3(\boldsymbol{B})\left(\right.$ wave $^{+/+}, p=0.0012 ;$ wave $\left.^{+/ m}, p=0.0035\right)$, session 8 on day $4(\boldsymbol{C})$ (wave $^{+/+}, p<0.0001$; wave $\left.{ }^{+/ m}, p<0.0004\right)$, and session 10 on day 5 (D) (wave ${ }^{+/+}, p<0.0001$; wave $^{+/ m}, p=0.0026$; wave $\left.^{m / m}, p<0.0001\right) . \boldsymbol{E}, \boldsymbol{F}, \mathrm{A}$ delayed probe trial was conducted $14 \mathrm{~d}$ after session 10 to measure long-term memory retention. $\boldsymbol{E}$, Representative swim-trace patterns for wild-type (wave ${ }^{+/+}$, left) and knock-in (wave $e^{m / m}$, right) mice in the delayed probe trial. Start position is marked by a black square, and a circle marks target location. $F$, Quantification of percentage time spent searching in each quadrant during the delayed probe trial (wave ${ }^{+/+},{ }^{* * *} p<0.0001 ;$ wave $\left.^{+/ m},{ }^{* *} p=0.005\right)$. G, Nonspatial learning and memory was measured by novel-object recognition ( $n=10$ each genotype; mean \pm SEM value is shown). Graph shows percentage time spent exploring the novel object for wild-type (wave $\left.{ }^{+/+}\right)$, heterozygous (wave $\left.{ }^{+/ m}\right)$, and knock-in (wave ${ }^{m / m}$ ) mice. ${ }^{*} p=0.036$ using one-way ANOVA; Tukey-Kramer, $p<0.05$ wild-type versus knock-in.

of endogenous WRP binding to the complex. Presumably, the remainder of the WAVE-associated WRP is retained via interactions with other WAVE binding partners. For example, a secondary means of WRP recruitment may be through its interaction with the Abl-interacting protein Abi-1. The same may be true for other components of the WAVE complex such as the Abl tyrosine kinase, which binds directly to WAVE-1 through its $\mathrm{SH} 3$ domain and can also be indirectly retained through its binding to the Abi proteins (Dai and Pendergast, 1995; Shi et al., 1995; Westphal et al., 2000). Thus, proteins within the WAVE-1 signaling complex use multiple sites of contact, and, at this time, we do not fully understand the role other protein-protein interactions play in recruiting WRP.

WRP is a candidate mental retardation gene that was identi- fied by positional cloning as the only gene disrupted in an individual with a balanced de novo translocation of chromosome $\mathrm{t}(\mathrm{X}$; 3)(p11.2;p25) (Endris et al., 2002). This patient exhibited the severe mental retardation and locomotor impairments that are associated with 3p-syndrome. Although other genes have also been implicated (Angeloni et al., 1999; Sotgia et al., 1999), 11 patients with 3p-syndrome mental retardation exhibited loss of heterozygosity for WRP. This is supportive of the hypothesis that reduced levels of this Racselective GAP protein is causally linked to impaired cognitive performance.

The wave $^{m / m}$ mice were engineered to have reduced levels of WRP associated with WAVE-1. This not only allowed us to focus on the role of a specific protein-protein interaction within the WAVE signaling complex but also provided us with a mouse model in which the reduced subcellular targeting of WRP might mimic a haploinsufficiency of the GAP protein. Behavioral analyses of these mice support this notion. Impairment in hippocampaldependent memory retention was particularly evident in the probe trial performance of the Morris water maze test (Fig. 7). Cognitive impairment in these knock-in animals could also be seen in their novel-object recognition performance. In contrast, other behaviors such as sensorimotor function were no different from wild-type mice and thus did not contribute to these memory impairments. These impairments were analogous to a subset of the cognitive defects observed previously in the WAVE-1 knock-out animals. Thus, recruitment of WRP to the WAVE-1 complex may be required to regulate certain aspects of memory retention. The additional cognitive defects observed in the WAVE-1 knock-outs may be attributed to targeting of other WAVE-1associated proteins. Interestingly, one common mechanism that may underlie some forms of mental retardation is the alteration of Rho GTPase signaling ( $\mathrm{Ra}$ makers, 2002; Newey et al., 2005). This is supported by studies that have identified multiple Rho GTPase signaling genes in both syndromic and nonsyndromic forms of mental retardation. Examples include the Rho GAP oligoprhenin-1, the Rac GEF ARGEF6/cool-2/ $\alpha$ pix, and the Rac-activated kinase PAK3 (Allen et al., 1998; Billuart et al., 1998; Kutsche et al., 2000).

Analyses of our genetically modified mice support the notion that WAVE-1 complexes play a role in the development or maintenance of neuronal connectivity. Live-cell imaging approaches demonstrate that the loss of WAVE-1 perturbs growth cone dynamics and alters neurite outgrowth. Paradoxically, an absence of WAVE-1 increases the extension velocity of the lamellipodia, yet the lamellipodia rarely extends to the tips of the filopodia. One potential explanation is that the elongated or spiky morphology 
of WAVE-1 null growth cones is symptomatic of less stable lamellipodia. This finding is compatible with reports that elevated membrane levels of the mammalian enabled (Mena)/ vasodilator-stimulated phosphoprotein (Vasp) proteins enhance the extension velocity of the lamellipodia yet reduce cell migration (Bear et al., 2000). Because Mena and Vasp are potential substrates for the WAVE-1-associated Abl tyrosine kinase and PKA, it is possible that local phosphorylation events could contribute to dynamic changes in the neuronal cytoskeleton (Loureiro et al., 2002). Consequently, one could imagine that actin with less branching may be unable to sustain the integrity of the lamellipodia for long enough to permit normal neurite outgrowth. Other work suggests that WAVE-1 is transported within neurons in a kinesin-1/collapsin response mediator protein 2 (CRMP-2)-dependent manner (Kawano et al., 2005). RNA interference (RNAi) knockdown of WAVE-1 inhibits CRMP-2stimulated axonal outgrowth and multiple axon formation. This is consistent with our evidence that WAVE-1 regulates growth cone morphology and neurite outgrowth but is at odds with evidence that inhibition of Arp2/3-stimulated neurite outgrowth (Strasser et al., 2004). Analogous RNAi studies in Drosophila show that loss of dWAVE inhibits lamellipodia as well as filopodial formation (Biyasheva et al., 2004). How these different findings fit together is not yet clear. One possibility is that distinct WAVE-1 complexes regulate growth cone morphology and neurite outgrowth. In some cases, these cytoskeletal signaling events may involve mechanisms that are independent of Arp2/3.

Actin reorganization within dendritic spines is a dynamic process. For example, fluorescence recovery after photobleaching experiments have calculated that $\sim 85 \%$ of the actin within dendritic spines turns over every $44 \mathrm{~s}$ and that actin dynamics can be regulated by synaptic activity (Star et al., 2002). Therefore, molecules that control actin dynamics have the capacity to profoundly influence spine development as well as synaptic transmission. Our quantitative analyses of Golgi-impregnated tissues reveal a reduction in spine density in neurons from WAVE-1 knock-out and mWAVE knock-in animals. These morphological changes were observed in both the CA1 region of the hippocampus and the outer layer of the cortex. Spinogenesis occurs not only during development but also in adulthood in response to plasticity-inducing stimuli (Moser et al., 1994). Transfection of dominant-negative WAVE-1 444-559, $\mathrm{R}_{512} \mathrm{~K}_{513} / \mathrm{EE}$ impairs spine development in vitro, suggesting that this pathway may play a role during development. We also observed an effect on spine morphology in these experiments, supporting the idea that WAVE-1 signaling to Arp2/3 regulates spine head shape. Interestingly, Abi-2 knock-out mice also show reductions in spine density as well deficits in learning and memory (Grove et al., 2004). Because the Abi proteins are ligands for WAVE-1, this suggests that the coordinated binding between these proteins may be critical for spine development. Our results showing that WRP and WAVE-1 coordinately regulate spinogenesis are consistent with recent observations that C $\mathrm{dk} 5$ (cyclin-dependent kinase 5) and PKA signaling also regulate spine morphology via WAVE-1 (Kim et al., 2006).

WAVE-1 null and knock-in mice also show differences in synaptic transmission and plasticity. In both cases, we measured reduced maximal fEPSP in neurons from genetically modified animals when compared with wild-type littermates. This is consistent with the reduced spine density we observe in both models. Furthermore, effective memory storage within a neural network is thought to depend on the bidirectional modulation of synaptic strength (Morris and Willshaw, 1989; Zeng et al., 2001). Our electrophysiological recordings from hippocampal slices show that WAVE-1 knock-out mice exhibit increased LTP and reduced LTD. These deficits in bidirectional synaptic plasticity are in good agreement with our previous characterization of a WAVE-1 null phenotype showing that these animals exhibit impaired behavioral learning and task-associated memory.

Interestingly, WAVE-1 null mice show elevated NMDAR responses relative to AMPAR responses. This apparent increase in the NMDA response implies that there may be an altered composition of synaptic glutamate receptors in WAVE-1 null mice. Indeed, this relative enhancement of NMDAR responsiveness is consistent with a bias toward greater LTP at the expense of LTD. mWAVE-1 knock-in mice are normal for early LTP and LTD but do have abnormal L-LTP, which is consistent with our behavioral data showing a specific impairment in memory retention. This correlation suggests the two are causally linked and strongly argue that WAVE-1 signaling plays a previously unsuspected role in regulating synaptic transmission and plasticity. However, we cannot rule out that additional synaptic abnormalities may exist these animals. Such aberrant signaling events could include reduced GABAergic tone, changes in glutamate receptor attachment to the actin cytoskeleton, ion channel trafficking, or alterations in the basal synaptic distribution. Future experiments will be necessary to test these hypotheses.

In summary, genetic and phenotypic analysis of WAVE-1 knock-out and mWAVE-1 knock-in mice reveal new evidence for the WAVE-1 signaling pathway in regulating neuronal connectivity. Alteration of this pathway impacts the expression of normal behaviors, including learning and memory. We also provide evidence that WAVE-1 signaling regulates growth cone dynamics, neurite outgrowth, and spinogenesis. Furthermore, the WAVE-1 pathway also plays a previously unappreciated role in regulating synaptic plasticity. These results imply that neuronal connectivity, glutamate receptor composition, and synaptic strength are encoded through dynamic actin remodeling that is facilitated by WAVE-1 signaling complexes.

\section{References}

Allen KM, Gleeson JG, Bagrodia S, Partington MW, MacMillan JC, Cerione RA, Mulley JC, Walsh CA (1998) PAK3 mutation in nonsyndromic X-linked mental retardation. Nat Genet 20:25-30.

Angeloni D, Lindor NM, Pack S, Latif F, Wei MH, Lerman MI (1999) CALL gene is haploinsufficient in a $3 \mathrm{p}$ - syndrome patient. Am J Med Genet 86:482-485.

Banker GA (1998) Culturing nerve cells, Ed 2. Cambridge, MA: MIT.

Bear JE, Rawls JF, Saxe III CL (1998) SCAR, a WASP-related protein, isolated as a suppressor of receptor defects in late Dictyostelium development. J Cell Biol 142:1325-1335.

Bear JE, Loureiro JJ, Libova I, Fassler R, Wehland J, Gertler FB (2000) Negative regulation of fibroblast motility by Ena/VASP proteins Cell 101:717-728

Benice TS, Rizk A, Kohama S, Pfankuch T, Raber J (2006) Sex-differences in age-related cognitive decline in $\mathrm{C} 57 \mathrm{BL} / 6 \mathrm{~J}$ mice associated with increased brain microtubule-associated protein 2 and synaptophysin immunoreactivity. Neuroscience 137:413-423.

Billuart P, Bienvenu T, Ronce N, des Portes V, Vinet MC, Zemni R, Carrie A, Beldjord C, Kahn A, Moraine C, Chelly J (1998) Oligophrenin 1 encodes a rho-GAP protein involved in X-linked mental retardation. Pathol Biol (Paris) 46:678.

Biyasheva A, Svitkina T, Kunda P, Baum B, Borisy G (2004) Cascade pathway of filopodia formation downstream of SCAR. J Cell Sci 117:837-848.

Carlisle HJ, Kennedy MB (2005) Spine architecture and synaptic plasticity. Trends Neurosci 28:182-187.

Cho KO, Hunt CA, Kennedy MB (1992) The rat brain postsynaptic density fraction contains a homolog of the Drosophila discs-large tumor suppressor protein. Neuron 9:929-942.

Dai Z, Pendergast AM (1995) Abi-2, a novel SH3-containing protein inter- 
acts with the c-Abl tyrosine kinase and modulates c-Abl transforming activity. Genes Dev 9:2569-2582.

Eden S, Rohatgi R, Podtelejnikov AV, Mann M, Kirschner MW (2002) Mechanism of regulation of WAVE1-induced actin nucleation by Rac1 and Nck. Nature 418:790-793.

Endris V, Wogatzky B, Leimer U, Bartsch D, Zatyka M, Latif F, Maher ER, Tariverdian G, Kirsch S, Karch D, Rappold GA (2002) The novel RhoGTPase activating gene MEGAP/ srGAP3 has a putative role in severe mental retardation. Proc Natl Acad Sci USA 99:11754-11759.

Etienne-Manneville S, Hall A (2002) Rho GTPases in cell biology. Nature 420:629-635.

Fukazawa Y, Saitoh Y, Ozawa F, Ohta Y, Mizuno K, Inokuchi K (2003) Hippocampal LTP is accompanied by enhanced F-actin content within the dendritic spine that is essential for late LTP maintenance in vivo. Neuron 38:447-460.

Grove M, Demyanenko G, Echarri A, Zipfel PA, Quiroz ME, Rodriguiz RM, Playford M, Martensen SA, Robinson MR, Wetsel WC, Maness PF, Pendergast AM (2004) ABI2-deficient mice exhibit defective cell migration, aberrant dendritic spine morphogenesis, and deficits in learning and memory. Mol Cell Biol 24:10905-10922.

Hinz B, Alt W, Johnen C, Herzog V, Kaiser HW (1999) Quantifying lamella dynamics of cultured cells by SACED, a new computer-assisted motion analysis. Exp Cell Res 251:234-243.

Hufner K, Higgs HN, Pollard TD, Jacobi C, Aepfelbacher M, Linder S (2001) The verprolin-like central (vc) region of Wiskott-Aldrich syndrome protein induces Arp2/3 complex-dependent actin nucleation. J Biol Chem 276:35761-35767.

Innocenti M, Zucconi A, Disanza A, Frittoli E, Areces LB, Steffen A, Stradal TE, Fiore PP, Carlier MF, Scita G (2004) Abil is essential for the formation and activation of a WAVE2 signalling complex. Nat Cell Biol 6:319-327.

Kaech S, Fischer M, Doll T, Matus A (1997) Isoform specificity in the relationship of actin to dendritic spines. J Neurosci 17:9565-9572.

Kawano Y, Yoshimura T, Tsuboi D, Kawabata S, Kaneko-Kawano T, Shirataki H, Takenawa T, Kaibuchi K (2005) CRMP-2 is involved in kinesin-1-dependent transport of the Sra-1/WAVE1 complex and axon formation. Mol Cell Biol 25:9920-9935.

Kim Y, Sung JY, Ceglia I, Lee KW, Ahn JH, Halford JM, Kim AM, Kwak SP, Park JB, Ho Ryu S, Schenck A, Bardoni B, Scott JD, Nairn AC, Greengard $P$ (2006) Phosphorylation of WAVE1 regulates actin polymerization and dendritic spine morphology. Nature 442:814-817.

Kim YT, Wu CF (1991) Distinctions in growth cone morphology and motility between monopolar and multipolar neurons in Drosophila CNS cultures. J Neurobiol 22:263-275.

Kutsche K, Yntema H, Brandt A, Jantke I, Nothwang HG, Orth U, Boavida MG, David D, Chelly J, Fryns JP, Moraine C, Ropers HH, Hamel BC, van Bokhoven H, Gal A (2000) Mutations in ARHGEF6, encoding a guanine nucleotide exchange factor for Rho GTPases, in patients with X-linked mental retardation. Nat Genet 26:247-250.

Liu P, Jenkins NA, Copeland NG (2003) A highly efficient recombineeringbased method for generating conditional knockout mutations. Genome Res 13:476-484.

Loureiro JJ, Rubinson DA, Bear JE, Baltus GA, Kwiatkowski AV, Gertler FB (2002) Critical roles of phosphorylation and actin binding motifs, but not the central proline-rich region, for Ena/vasodilator-stimulated phosphoprotein (VASP) function during cell migration. Mol Biol Cell 13:2533-2546.

Machesky LM, Insall RH (1998) Scarl and the related Wiskott-Aldrich syndrome protein, WASP, regulate the actin cytoskeleton through the Arp $2 / 3$ complex. Curr Biol 8:1347-1356.

Moon SY, Zheng Y (2003) Rho GTPase-activating proteins in cell regulation. Trends Cell Biol 13:13-22.

Morris RG, Willshaw DJ (1989) Memory. Must what goes up come down? Nature 339:175-176.

Morris RG, Garrud P, Rawlins JN, O'Keefe J (1982) Place navigation impaired in rats with hippocampal lesions. Nature 297:681-683.
Moser MB, Trommald M, Andersen P (1994) An increase in dendritic spine density on hippocampal CA1 pyramidal cells following spatial learning in adult rats suggests the formation of new synapses. Proc Natl Acad Sci USA 91:12673-12675.

Newey SE, Velamoor V, Govek EE, Van Aelst L (2005) Rho GTPases, dendritic structure, and mental retardation. J Neurobiol 64:58-74.

Ng J, Nardine T, Harms M, Tzu J, Goldstein A, Sun Y, Dietzl G, Dickson BJ, Luo L (2002) Rac GTPases control axon growth, guidance and branching. Nature 416:442-447.

Nozumi M, Nakagawa H, Miki H, Takenawa T, Miyamoto S (2003) Differential localization of WAVE isoforms in filopodia and lamellipodia of the neuronal growth cone. J Cell Sci 116:239-246.

Oh MC, Derkach VA (2005) Dominant role of the GluR2 subunit in regulation of AMPA receptors by CaMKII. Nat Neurosci 8:853-854.

Okamoto K, Nagai T, Miyawaki A, Hayashi Y (2004) Rapid and persistent modulation of actin dynamics regulates postsynaptic reorganization underlying bidirectional plasticity. Nat Neurosci 7:1104-1112.

Ramakers GJ (2002) Rho proteins, mental retardation and the cellular basis of cognition. Trends Neurosci 25:191-199.

Ramon-Moliner E (1970) The Golgi-Cox technique. New York: Springer.

Rodal AA, Sokolova O, Robins DB, Daugherty KM, Hippenmeyer S, Riezman H, Grigorieff N, Goode BL (2005) Conformational changes in the Arp2/3 complex leading to actin nucleation. Nat Struct Mol Biol $12: 26-31$.

Rohatgi R, Ma L, Miki H, Lopez M, Kirchhausen T, Takenawa T, Kirschner MW (1999) The interaction between N-WASP and the Arp $2 / 3$ complex links Cdc42-dependent signals to actin assembly. Cell 97:221-231.

Schenck A, Qurashi A, Carrera P, Bardoni B, Diebold C, Schejter E, Mandel JL, Giangrande A (2004) WAVE/SCAR, a multifunctional complex coordinating different aspects of neuronal connectivity. Dev Biol 274:260-270.

Shi Y, Alin K, Goff SP (1995) Abl-interactor-1, a novel SH3 protein binding to the carboxy-terminal portion of the Abl protein, suppresses v-abl transforming activity. Genes Dev 9:2583-2597.

Soderling SH, Binns KL, Wayman GA, Davee SM, Ong SH, Pawson T, Scott JD (2002) The WRP component of the WAVE-1 complex attenuates Rac-mediated signalling. Nat Cell Biol 4:970-975.

Soderling SH, Langeberg LK, Soderling JA, Davee SM, Simerly R, Raber J, Scott JD (2003) Loss of WAVE-1 causes sensorimotor retardation and reduced learning and memory in mice. Proc Natl Acad Sci USA 100:1723-1728

Sotgia F, Minetti C, Lisanti MP (1999) Localization of the human caveolin-3 gene to the D3S18/D3S4163/D3S4539 locus (3p25), in close proximity to the human oxytocin receptor gene. Identification of the caveolin-3 gene as a candidate for deletion in 3p-syndrome. FEBS Lett 452:177-180.

Star EN, Kwiatkowski DJ, Murthy VN (2002) Rapid turnover of actin in dendritic spines and its regulation by activity. Nat Neurosci 5:239-246.

Steffen A, Rottner K, Ehinger J, Innocenti M, Scita G, Wehland J, Stradal TE (2004) Sra-1 and Nap1 link Rac to actin assembly driving lamellipodia formation. EMBO J 23:749-759.

Strasser GA, Rahim NA, VanderWaal KE, Gertler FB, Lanier LM (2004) $\operatorname{Arp} 2 / 3$ is a negative regulator of growth cone translocation. Neuron 43:81-94.

Volkmann N, Amann KJ, Stoilova-McPhie S, Egile C, Winter DC, Hazelwood L, Heuser JE, Li R, Pollard TD, Hanein D (2001) Structure of Arp2/3 complex in its activated state and in actin filament branch junctions. Science 293:2456-2459.

Westphal RS, Soderling SH, Alto NM, Langeberg LK, Scott JD (2000) Scar/ WAVE-1, a Wiskott-Aldrich syndrome protein, assembles an actin- associated multi-kinase scaffold. EMBO J 19:4589-4600.

Zeng H, Chattarji S, Barbarosie M, Rondi-Reig L, Philpot BD, Miyakawa T, Bear MF, Tonegawa S (2001) Forebrain-specific calcineurin knockout selectively impairs bidirectional synaptic plasticity and working/episodiclike memory. Cell 107:617-629. 